\title{
C-STEM Girls Computing and Robotics Leadership Camp
}

\author{
Sruti Modekurty \\ Judy Fong, UC Davis
}

Judy Fong is an undergraduate computer science student at the University of California, Davis where she has designed and implemented a computer science tutoring program. She is the president of the Computing and Robotics Outreach Club. During the summer last year, she acted as a coach at the Girls Computing and Robotics Leadership Camp.

\section{Prof. Harry H. Cheng, University of California, Davis}

Harry H. Cheng is a Professor in the Department of Mechanical and Aerospace Engineering, Graduate Group in Computer Science, and Graduate Group in Education at the University of California, Davis, where he is also the Director of the UC Davis Center for Integrated Computing and STEM Education (http://c-stem.ucdavis.edu) and Director of the Integration Engineering Laboratory. His current research includes developing computing and robotics technologies and integrate them into STEM education in both formal and informal settings for integrated learning. From 1989 to 1992, he was a Senior Engineer for robotic automation systems with the Research and Development Division, United Parcel Service. He has authored and coauthored more than 170 papers in refereed journals and conference proceedings. $\mathrm{He}$ holds two U.S. patents. He is the author of the book "C for Engineers and Scientists: An Interpretive Approach" (McGraw-Hill, 2009). He is the co-founder of SoftIntegration, Inc. and Barobo, Inc. He received a M.S. degree in mathematics and a Ph.D. degree in mechanical engineering from the University of Illinois at Chicago in 1986 and 1989, respectively. He is a Fellow of the American Society of Mechanical Engineers and a Senior Member of IEEE. Dr. Cheng received the ASME's MESA Achievement Award for a cumulative contribution to the field of Mechatronic and Embedded Systems and Applications, a Research Initiation Award from the National Science Foundation, the Best Paper Award and Best Student Paper Award at the IEEE/ASME International Conference on Mechatronic and Embedded Systems and Applications, the Procter and Gamble Best Paper Award as well as the Waldron Award at the Applied Mechanisms and Robotics Conference. He received an Outstanding Contribution Award from United Parcel Service, Inc. He was the General Chair of the 2009 ASME/ IEEE International Conference on Mechatronic and Embedded Systems and Applications and the Program Chair of the 2006 IEEE/ASME International Conference on Mechatronic and Embedded Systems and Applications. 


\title{
C-STEM Girls Computing and Robotics Leadership Camp
}

\begin{abstract}
In the summer of 2013, the UC Davis C-STEM Center hosted a one-week Girls Computing and Robotics Leadership Camp for 14 middle school girls from the greater Sacramento region. This camp set out to motivate girls to learn science, technology, engineering, and math (STEM) concepts through a fun and exciting robotics-based curriculum. Emerging as leaders, the participants inspire other young girls to gain interest in science and technology. Three college female students led the camp with the help of six high school female student assistant coaches. Through this experience the 14 girls learned the basics of robotics, principles of engineering, and essentials of $\mathrm{C} / \mathrm{C}++$ programming. In addition, they learned important life skills including teamwork, presentation skills, leadership skills, self-assurance, and breaking gender stereotypes. Women professionals in various science and engineering fields also met and discussed with the participants helping them visualize a future career in STEM and gain exposure to the variety of options available to them. As a culminating project the girls who participated in the camp created multi-media video presentations with robotics, similar to the RoboPlay Video Competition, and made presentations in front of parents and peers. The girls were given robotics kits to take back to their middle schools so they can start computing and robotics clubs of their own. Coaches and assistant coaches continue to mentor girls over the academic school year to facilitate the development of these clubs and their participation in RoboPlay Competition. In this paper, the curriculum and lessons learned through this camp will be presented.
\end{abstract}

\section{Introduction}

Currently there is a significant gender gap in engineering and science. A recent article in the New York Times reported ${ }^{1}$, even as women make significant headway in fields from law, business, chemistry, and biology, the doors to technology, one of the fastest-growing sectors of the economy, remains virtually closed to women. Just 5.7 percent of employed women in the United States work in the computer industry, and only about 2 percent of women have a degree in a high-tech field, according to Catalyst ${ }^{2}$, a prominent research firm studying women and business. If we look at the workforce pipeline, women barely make up 18 percent of undergraduates in engineering schools across the US ${ }^{3}$. Concerning the global economy, if the US wants to be competitive in technology development and provide an equal opportunity for half its population, the gender gap in engineering and technology needs to be closed.

Robotics is an interdisciplinary field that involves a variety of math, computing, and engineering concepts. Through robotics, K-12 students become engaged and excited about learning math, computing, and engineering concepts. The UC Davis Center for Integrated Computing and STEM Education (C-STEM) ${ }^{4}$ has successfully integrated computing and robotics into STEM education in grades K-14. With funding from the National Science Foundation, the National Center for Women and Information Technology (NCWIT) AspireIT Middle School Outreach Program ${ }^{5,6}$, the C-STEM Center organized a one-week Girls Leadership Camp on Computing and Robotics for middle school girls on July 22-26, $2013^{7,8}$.

The goal of the camp is to motivate girls in middle school to learn science, technology, 
engineering, and math (STEM) concepts through a fun and exciting robotics-based curriculum. We want them to emerge as leaders amongst their peers and inspire other young girls to gain interest in science and technology. The camp is designed to be engaging, allowing the campers to understand the material quickly in a fun and interactive way. Within the curriculum and various activities, we wanted to incorporate general themes females face in STEM fields, especially in the Computer Science community. For example, some of these themes include: breaking gender stereotypes, dealing with peer pressure, having an interest but lacking resources, etc. Different from the majority of other camps, this camp has unique teaching styles, structures, and learning which extends beyond the duration of the one-week camp.

\section{Integrated Computing and STEM Education}

The UC Davis C-STEM Center aims to transform computing, science, technology, engineering, and mathematics (C-STEM) education in both formal and informal K-14 programs through integrated learning, guided by two key objectives:

-Close the achievement gap by broadening participation of students traditionally underrepresented in computing and STEM related careers and post-secondary study.

-Develop students’ 21st century problem-solving skills to tackle real world concerns through integrated computing and STEM education.

Through cutting edge research, with funding from the National Science Foundation, the CSTEM Center, in collaboration with our industry partners, has developed innovative educational computing and robotics technologies ${ }^{9}$ for K-14 hands-on learning. By working with K-14 educators, the C-STEM Center integrates computer programming and robotics into teaching STEM subjects through project-based computing and robotics activities, integrated curriculum, and hands-on personalized and collaborative learning strategies aligned with Common Core State and CTE Standards. This integration helps students make meaningful connections between STEM topics and real-life applications as well as develop students' critical thinking and problem-solving skills. The Center focuses on Algebra topics, the gatekeeper for STEM disciplines, to help close the achievement gap, engage traditionally underrepresented groups and at risk students in learning STEM subjects while preparing all students to be college and career ready. The Center focuses on broadening participation of female and underrepresented minorities in computing and developing students' computer-aided problem-solving skills through programs such as this leadership camp.

\subsection{Reconfigurable Modular Robot Technology}

Most commercial robots are developed for special applications. Lego $\mathrm{NXT}^{10}$ and Vex ${ }^{11}$ robots are mainly designed for engineering and robotics programs as well as afterschool programs. The capability of NXT is rather limited, especially for learning Algebra and other math subjects. For example, a Lego NXT set has over 500 parts. Many math classes have 30 or more students and would require each student to have their own robot for personalized learning. This would lead to the math teacher managing over 15,000 parts. As another example, writing a program to move two robots at different constant speeds, and collecting distances and time in 
real-time and plotting them are difficult.

Working with the UC Davis C-STEM Center, Barobo, Inc., a UC Davis spinoff company ${ }^{12}$, has developed modular robots: iMobot, Mobot, and Linkbot for STEM education. Linkbot shown in Figure 1 is the latest version, specially designed for math and science education. Linkbot is designed as a building block, with a single module acting as a fully functional robot. Each Linkbot module has two controllable degrees of freedom, powered by an internal rechargeable lithium-ion battery good for all day use. SnapConnectors allow modules to be snapped together without special tools to create a snake, tank, humanoid, and any other system imaginable. Some additional accessories can also be made from 3D printing to fit with the Linkbots. Many of Linkbots CAD files are available for 3D printing.

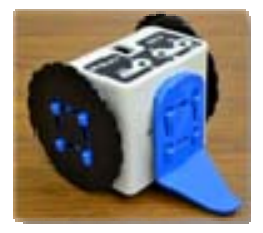

Figure 1: The Linkbot.

Learning robotics with Linkbots starts with a simple Graphical User Interface (GUI). However, the distinguishing factor between a robot and other mechanical devices is its reprogrammability. Programming is needed for more sophisticated applications of robots. Programming the Linkbot is extremely simple and easy, and especially reinforces mathematics concepts. For example, the Ch program shown in Figure 2 moves a Linkbot a distance of 5 inches, with the radius of the wheels of set as 1.75 inches. Students can change the wheels of the robot easily to learn various math concepts related to the radius, ratios, proportions, circumference, distances, speed, etc.

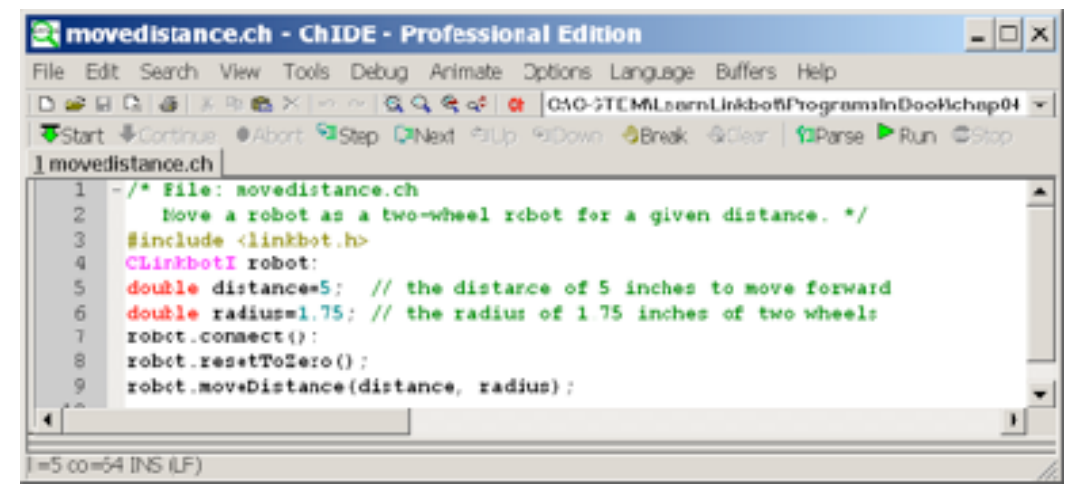

Figure 2: A Ch program to move a Linkbot 5 inches.

\subsection{RoboPlay Competition}

The Linkbot and its programming simplicity have been tested in classroom teaching, after school programs, and the RoboPlay Competition ${ }^{13}$ held at UC Davis on May 5, 2013. Students, some as young as $5^{\text {th }}$ and $6^{\text {th }}$ grade, compete at the competitions, effectively learning math 
concepts through problem solving.

The RoboPlay Video Competition is designed for K-12 students to play with robots while exploring their creativity in writing, art, music, choreography, design, video editing, and film production; and at the same time seamlessly learn computing and STEM subjects. The handling of robot coordination between multiple modules and music requires not only teamwork in designing a well-organized visual performance but also the math and programming skills to produce the desired actions for robots. The competitions will enable students working in different interest groups to explore the basic concepts of C-STEM in conjunction with their artistic and musical talents.

\section{Curriculum of the Camp}

\subsection{Robotics Curriculum}

The main curricular focus of the camp was based on the Linkbot curriculum described earlier. Further describing the programming environment, the integrated development environment ( IDE), associated with the Linkbot is a user-friendly $\mathrm{C} / \mathrm{C}++$ interpreter called $\mathrm{Ch}^{14}$. Computer programming knowledge in $\mathrm{C} / \mathrm{C}++$ is a fundamental skill for today's students as described in "Ten Reasons to Teach and Learn Computer Programming in $C^{\prime \prime}{ }^{15} . \mathrm{C} / \mathrm{C}++$ is widely used in both industries and academia. Ch was designed especially for beginners to learn programming in $\mathrm{C} / \mathrm{C}++$, as well as scientific visualization and mathematical computing.

Initially campers were taught fundamental engineering and programming concepts. Once the basics were established, the curriculum became more advanced and required applying the design process for the Linkbot programs.

The Linkbots can be connected together using connectors and 3D printed wheels. Since the robots are easily pieced together with almost Lego-like ease, the girls were quickly able to assemble them into larger shapes like a snake. This distinguishing factor is what sets the Linkbots apart from other currently available robotics-based curriculum. Most robots are geared towards building, resulting in most of the time spent fiddling with pieces. Girls seem to be less inclined towards such building, and therefore may be deterred from the beginning. Due to their easily assembly, the Linkbots emphasis is placed on programming. Through the Linkbots, many girls learned their first programming concepts and programming language.

\subsection{Life Skills Curriculum}

In addition to the technical curriculum, the camp aimed to instill skills that would be helpful throughout life, and enable the campers to emerge as leaders amongst their peers. Each day, the coaches or assistant coaches gave a presentation about a skill (i.e. communication) and had them participate in accompanying activities that would help them learn and practice the skill.

Each morning started with a video followed by a discussion related to being a girl in STEM fields, using the Socratic method. For example, one morning the coaches asked each of the girls why they felt there were not as many girls as boys in STEM and computing fields. Their responses included “it’s difficult and sometimes girls don’t always get the same help and 
encouragement that boys do," and "sometimes they want to be involved, but don't know how to or have the resources to [get involved]." One camper even said, "Boys like to dominate and say they have to do it their way and don't listen to what we're saying”. To address the girls' concerns, the coaches asked them how they think the situation could be improved.

At the end of the day, the campers gathered around to hear the coaches and assistant coaches answer questions from the question box (a box where the girls could place any questions they wanted to ask, especially if they were too shy). The questions ranged from material learned during the camp to college life to preparatory high school classes to go into Computer Science. All the coaches answered each question giving the middle school girls a wide range of responses from different age groups.

\subsection{Learning Environment}

A unique and wholesome learning environment for the girls was achieved in several ways. The camp was held on a college campus, UC Davis giving the campers a glimpse of college life. Enhancing this experience, the campers visited labs, were given tours of the campus and dorms, and ate in the campus dining hall. These visitations were not only to give them a break, but also to excite and encourage them to continue onto higher education. Another unique aspect of the program was the support structure. The campers themselves were in middle school, the six assistant coaches were in high school, and the coaches were college students. The program coordinators wanted all levels present, thus giving the campers someone to relate to in all stages of their life going forward and helping them visualize themselves completing high school, college and eventually entering their career. Another intriguing aspect of the camp was the guest speakers. Women engineers from different areas of engineering came in to speak to the girls about what they do, issues they may have faced as women in engineering and how they overcame it. They also provided continuity to the pathway, portraying to the girls that they could one day become an intelligent, successful engineer.

The curriculum also allowed for personalized learning. Initially when going over the material, each girl used her own robot and computer to learn. This ensured that each girl understood the fundamentals. While they were all taught as a group, the assistant coaches would go around helping and ensuring each girl was keeping up. After completing basic programming concepts and robot commands, they were assigned groups to work on two different projects. The coaches chose the groups, instead of letting the girls choose their own, so that all the groups would be at a similar level, without one group having an advantage over the others. The groups were decided so they would be balanced age wise and skill wise. Within the groups, the campers were encouraged to come up with specific roles to make sure that everyone was participating and felt included.. The campers learned valuable skills about teamwork since they will not always be able to choose who they work with. This was also a way to encourage increased creativity through collaboration and as a way for peer mentoring. If the coaches saw someone in the group struggling with a concept, they encouraged the members who understood it to teach the struggling member. Through this method, it was found that often they learned it better from their peers.

Once sufficient programming knowledge had been gained, the girls attempted to solve a programming problem as a class. First they figured out the logic behind the problem. Then, they 
worked it out using pseudo code. Next, they programmed and debugged it. Finally they tested it out on the robots, leading to further tweaks in their algorithm. Successful attempts really encouraged them to continue programming. This enthusiasm was also evident in their projects.

\subsection{Project - Based Learning}

One of the projects was designed to help the campers purely increase their technical skills. Using challenges from the May 2013 RoboPlay competition, the coaches and assistant coaches set up an obstacle course with tasks of increasing difficulty. For example, the first was designed to be fairly simple. The robot must start at the end of the board and drive up to a line but not go past it. Through this challenge, the girls learned how to drive the motors, set the speed, measure a distance on the board, and convert it all into motor rotations for the robot. For more challenging task, the robot was required to start in Zone A, touch Zone B, and finish in Zone 3. These three zones were spread out on the board. This taught them about turning, program modularity, error checking, and the importance of testing small portions of code.

The second project was a video project. The campers were asked to identify a real-world problem and design a solution using robotics. Using the Linkbots, they then had to create a video to explain the problem and their solution. This project was designed to show them how they can use their skills in engineering, computing, and robotics to solve problems, something girls seem to identify with. They were also able to use their seemingly natural inclination towards arts and crafts to design props and costumes. The response from the girls was highly encouraging. They had no problem finding and designing a solution and came up with such great presentations, all in a very short period of time. For example, one of the groups picked the problem of littering. They filmed an elaborate skit, with a background story and a solution that involved robots that went around picking up litter. The most encouraging part of this particular group was they were so enthusiastic about everything and they were the youngest of all the campers.

\subsection{Continuation}

The model for the camp extends beyond the 1-week instruction. In place is a system to ensure the sustenance and growth of the program. By teaching the girls and developing their leadership skills, the aim of the program is to inspire them to go back to their school to teach their peers. Each of the campers was allowed to borrow a Linkbot for the year and given guidelines for starting a club, finding a teacher to mentor, etc. The hope is these clubs will then come back and participate in the C-STEM RoboPlay Competition each May, inspiring the continuation of learning. The coaches and assistant coaches mentor the clubs, keeping in contact with the leaders and providing guidance.

Further, the program coordinators want to study how the program has impacted the girls, through the next several years, ideally through higher education. Girls headed to high school in 2014 can become assistant coaches for the camp, in order to nurture their leadership potential and to provide example of a veteran camper for the new participants. Eventually, they can become coaches and carry on the legacy of the program. 


\section{Survey Data and Analysis Results}

Campers were handed anonymous surveys in order to evaluate the camp. The following charts and quotes represent the results obtained about the camp. The survey included 9 questions about what the campers liked or did not like and their confidence level/abilities for various skills after having participated in the camp. Overall, the results look very promising, with particularly notable data highlighted.

\section{(1) What was your favorite part of this program?} Theme 1: interact with the robot

- learning about how to program the robots and see the robots come to life

- When your program works and you get to see Linkbot move

- actually make the robots come to life on the computer

- Programming the robots and seeing that it worked

- Being able to program and code the robots

\section{Theme 2: students feel they were playing}

- Getting to play with robots.

- Learning new things

- My favorite part was just messing around with the programs \& Linkbots

- Playing with the robots and learn new things

- Participating in the obstacle course project and video project

- the video project because I got to make a film and program

(2) What was your least favorite part of this program? Theme 1: robot malfunction

- My least favorite part of this program was when the robots wouldn't response

- My least favorite part was when the robots would malfunction

- When I'd have worked on a program all day \& the program would crash

- When the web program crashes

- I didn’t like when the Linkbot would stop working

\section{Theme 2: debugging or searching for errors within codes}

- When your programs have errors and you can’t find what's wrong

- My least favorite part is when you think you have the distance and the degrees perfectly, but it is actually way off

- Not getting to choose our groups

- I wish it (the camp) was longer than a week.

- The snacks

- I didn’t agree with one of our guest speaker points on leadership. I believe leadership is a quality, girls don't have to be good leaders. 
- Waiting for other people to finish

\begin{tabular}{|c|c|c|c|c|c|c|c|c|c|c|}
\hline \multirow{2}{*}{$\begin{array}{l}\text { (3) Right now, How confident are } \\
\text { you in your ability to... } \\
\text { Design Computer games }\end{array}$} & \multicolumn{2}{|c|}{$\begin{array}{l}\text { Don't know } \\
\text { / never } \\
\text { tried }\end{array}$} & \multicolumn{2}{|c|}{$\begin{array}{c}\text { very } \\
\text { confident }\end{array}$} & \multicolumn{2}{|c|}{ confident } & \multicolumn{2}{|c|}{$\begin{array}{c}\text { a little } \\
\text { confident }\end{array}$} & \multicolumn{2}{|c|}{$\begin{array}{l}\text { not at all } \\
\text { confident }\end{array}$} \\
\hline & 9 & $64 \%$ & 1 & $7 \%$ & 1 & $7 \%$ & 2 & $14 \%$ & 1 & $7 \%$ \\
\hline use new computer software & 2 & $14 \%$ & 8 & $57 \%$ & 2 & $14 \%$ & 1 & $7 \%$ & 1 & $7 \%$ \\
\hline solve computer software problem & 0 & $0 \%$ & 1 & $7 \%$ & 2 & $14 \%$ & 10 & $71 \%$ & 1 & $7 \%$ \\
\hline program computer & 3 & $21 \%$ & 1 & $7 \%$ & 8 & $57 \%$ & 1 & $7 \%$ & 1 & $7 \%$ \\
\hline think of new technology inventions & 1 & $7 \%$ & 9 & $64 \%$ & 3 & $21 \%$ & 1 & $7 \%$ & 0 & $0 \%$ \\
\hline create new technology inventions & 0 & $0 \%$ & 4 & $29 \%$ & 2 & $14 \%$ & 4 & $29 \%$ & 4 & $29 \%$ \\
\hline
\end{tabular}

(4) If the program you just attended INCREASED your confidence in any of these areas (Q4), tell me about that.

\section{the field}

Theme 1: student explore to robotic and programming improves their confidence in

- Well, I learned more code and programming

- I probably would have never known how to program computer without this program and now I'm more confident about programming computers.

- Before this program, I had no experience with robotics, so this camp increased my confidence a lot

- Before this program, I didn't know anything about robotics. Now, I feel confident about programming. I would like to learn more.

\section{Theme 2:}

- They helped me learn more about computer and increased my confidence in this area mainly.

- I feel that I am a bit more computer smart

- It increased my confidence in programming

- The C-STEM robotics camp increased my confidence

- The program increased my confidence in programming robots

\begin{tabular}{|c|c|c|c|c|c|c|c|c|}
\hline $\begin{array}{l}\text { (5) Please mark your level of } \\
\text { agreement or disagreement with the } \\
\text { following sentence. }\end{array}$ & \multicolumn{2}{|c|}{$\begin{array}{l}\text { Strongly } \\
\text { Agree }\end{array}$} & \multicolumn{2}{|c|}{ Agree } & \multicolumn{2}{|c|}{ Disagree } & \multicolumn{2}{|c|}{$\begin{array}{l}\text { Strongly } \\
\text { Disagree }\end{array}$} \\
\hline $\begin{array}{l}\text { Important people in my life think it's } \\
\text { good for me to learn about technology }\end{array}$ & 8 & $57 \%$ & 6 & $43 \%$ & 0 & $0 \%$ & 0 & $0 \%$ \\
\hline $\begin{array}{l}\text { people like me can do well learning } \\
\text { technology }\end{array}$ & 7 & $50 \%$ & 6 & $43 \%$ & 1 & $7 \%$ & $v$ & $0 \%$ \\
\hline $\begin{array}{l}\text { Other students think it's cool that I learn } \\
\text { about technology }\end{array}$ & 1 & $7 \%$ & 7 & $54 \%$ & 5 & $36 \%$ & 0 & $0 \%$ \\
\hline
\end{tabular}




\begin{tabular}{|l|ll|ll|ll|ll|}
\hline $\begin{array}{l}\text { People like me can do well in } \\
\text { technology job }\end{array}$ & 7 & $\mathbf{5 4 \%}$ & 5 & $38 \%$ & 0 & $0 \%$ & 1 & $8 \%$ \\
\hline $\begin{array}{l}\text { People like me can create new } \\
\text { technology inventions }\end{array}$ & 6 & $\mathbf{4 6 \%}$ & 5 & $38 \%$ & 2 & $14 \%$ & 0 & $0 \%$ \\
\hline
\end{tabular}

(6) If you believe you would have answered these questions differently before the AspireIT program, tell me about that.

- I learned more and changed my aspect in things.

- If I hadn’t have taken this program I would never be interested in computer science

- I think programming made me think about how anyone can enter technology career or go into technology classes

- I would definitely answer the questions differently because I had no prior experience with robotics

- This program made me more confident

- My answers will still be the same

- To be honest, I wasn't very good with computers and I didn't know what coding was until they taught me

- I wouldn't have believed I could do well in a job

- I probably would disagree for all of them because I didn’t know about programming before this.

\begin{tabular}{|c|c|c|c|c|c|c|c|c|}
\hline \multirow{2}{*}{$\begin{array}{l}\text { (7) How much would you like to ... } \\
\text { Take future classes in computer game } \\
\text { design }\end{array}$} & \multicolumn{2}{|c|}{ A lot } & \multicolumn{2}{|c|}{$\begin{array}{l}\text { Pretty } \\
\text { much }\end{array}$} & \multicolumn{2}{|c|}{ A little } & \multicolumn{2}{|c|}{ Not at all } \\
\hline & 4 & $29 \%$ & 4 & $29 \%$ & 5 & $36 \%$ & 1 & $7 \%$ \\
\hline $\begin{array}{l}\text { Take future classes in computer } \\
\text { programming }\end{array}$ & 8 & $57 \%$ & 3 & $21 \%$ & 2 & $14 \%$ & 1 & $7 \%$ \\
\hline $\begin{array}{l}\text { Take future classes learning how to } \\
\text { create new technology inventions }\end{array}$ & 7 & $50 \%$ & 4 & $29 \%$ & 2 & $14 \%$ & 1 & $7 \%$ \\
\hline Get a college degree & 14 & $100 \%$ & 0 & $0 \%$ & 0 & $0 \%$ & 0 & $0 \%$ \\
\hline $\begin{array}{l}\text { Get a computing or technology-related } \\
\text { degree }\end{array}$ & 7 & $50 \%$ & 5 & $36 \%$ & 2 & $14 \%$ & 0 & $0 \%$ \\
\hline $\begin{array}{l}\text { get a technology-related job when you } \\
\text { get older }\end{array}$ & 8 & $57 \%$ & 3 & $21 \%$ & 2 & $14 \%$ & 1 & $7 \%$ \\
\hline
\end{tabular}

(8) If the program you just attended CHANGED your ideas about your future, tell us about that.

Theme 1:

- I want to be a math teacher but after this program I want to be a computer scientist 
- Before this program, I wanted to be in the field of genetics, now, I want to get into technology.

- I now want to go into a job with technology.

- I thought I wanted to be an engineer that builds bridges and buildings, now I am interested in computer science.

- Yes, it made me confident to stay in programming at school \& get a computing - related career

- Wanted to be something else when I grew up, but now I wanted to work with programming.

\section{Theme 2: student reflection}

- The program explained to me different career choices \& helped me think about which I liked.

- Not to be afraid about technology.

- Computer science was something I didn’t even consider

- I didn’t think I would like programming

- I It was an inspiring program, although I would still like to be a marine biologist

\section{(9) Just for research purpose, please tell us about yourself:}

\begin{tabular}{|r|c|}
\hline \multicolumn{1}{|c|}{ Ethnicity } & $\mathrm{n}=14$ \\
\hline African American/Black & 3 \\
\hline Asian/Pacific Islander & 5 \\
\hline Hispanic/Latina & 2 \\
\hline Wative American/American Indian & \\
\hline White/Caucasian & 6 \\
\hline Person with Disability & \\
\hline
\end{tabular}

Out of 14 girls, there was a wide distribution of ethnicities: 6 Caucasian; 2 Hispanic; 5 Asian; and 3 African American. It appears that some girls identify themselves in two categories. When they were asked to reflect on the program, the majority of responses indicated that they had previously viewed technology negatively or had not even considered it as a possible career choice. However, the campers stated that the program had helped open their eyes to the possibilities of computer science and other engineering and technology fields. Even for the more conservative responses, they still indicated a more positive view of the STEM fields due to their experience at the camp. Many of the campers now strongly wish to pursue some degree of programming in their careers. 57\% of respondents wished to pursue computer-programming classes later on and 50\% also wanted to create new technological inventions. All of the campers said they want to get a college degree and $50 \%$ of them even said they really want to get a computing or technology-related degree. This is a huge increase from the beginning of the camp when some of the campers had never tried programming or engineering. Also, 93\% of respondents indicated they would want to get a technology related job as an adult at least a little bit, with an overwhelming 57\% saying they really want a technology related job. 
All of the girls responded that their favorite part of the camp was watching their program for the robot come to life. This shows that including robotics into a computing and engineering curriculum is an effective way to get girls interested in the STEM fields. To counter the positive effects of using robots, the middle school girls' biggest complaint about the camp were actually about the times the robots would malfunction. But it could mean that after the robots reliability is improved, the C-STEM robotics curriculum in K-12 education could be a common and more widely used method to add more females to the STEM fields. From the surveys, the campers also tend to identify more with being able to solve software problems, to use new software, and to succeed in a technology job. 8 out of 14 campers also said they have people in their lives encouraging them to learn more about technology. This is a positive factor and if the camp can encourage role models for young girls to keep showing and telling them to learn more about technology, this could help close the gender gap within the computing and engineering fields. $54 \%$ of the campers also said that their peers consider learning technology as cool. This kind of outlook is encouraging because it means that being technologically inclined is not a stigma, not the popular opinion in middle school. Overall, the results look very promising.

Overall, the girls and their parents gave the experience a very positive response. The only complaints received were about technical glitches since the robots used at the camp were still prototypes under development. Since then, all these glitches have been fixed. Another aspect the girls reported they didn't enjoy as much was the leadership curriculum; they wanted to spend more time on the robotics aspect.

Some of the girls did not even know how to use a computer effectively, being so very used to only using mobile devices. One camper attested, "I feel that I am a bit more computer smart."

Not only did they learn about computers, they also learned social and personal skills, crucial skills for any job. "The C-STEM robotics camp increased my confidence" answered another middle school girl. Some of these positive outlooks were directly related to the robotics curriculum. "Before this program, I didn’t know anything about robotics. Now, I feel confident about programming. I would like to learn more."

This program also exposed many of the girls programming in computer science as a potential career for the first time. "I wanted to be a math teacher but after this program I want to be a computer scientist," stated a student. Yet another declared, "Before this program, I wanted to be in the field of genetics, now, I want to get into technology."

A common theme from the feedback is that these girls are more interested in technology, computer programming, and computer science. In addition, they are more confident in pursuing computing and STEM related careers. All girls participating in the camp would like to pursue a post-secondary study in the STEM fields.

\section{Lessons Learned}

To summarize, the following are the important lessons learned from the program: peer mentoring, engaging in computing through robotics with computer programming in a user friendly $\mathrm{C} / \mathrm{C}++$ interpreter $\mathrm{Ch}$, and real world technological applications. The program was specially structured to enable highly effective peer mentoring, allows the girls to relate to each other and reinforce the learned material better. For many of the girls, this camp was their first 
time using and playing with robots and computer programming. Through their desire to make the robots move, the camp taught the girls programming and programming concepts they can use if they choose to pursue an engineering or computer science field. Since many of the girls were not very familiar with computers, they also became more familiar with computers and using them in a structured setting.

\section{Future Plans}

Since this was the first year implementing the program, there is much room for improvement. Increased recruitment is among the top priorities for the next year, ideally attracting a diverse pool of students. Because we started the recruitment of the campers later, we accepted all 14 applicants for participating in the camp. We want students from all socioeconomic and ethnic background with various levels of academic accomplishment, to observe the effectiveness of the program. With an increased number of applicants, the program coordinators can pick students who would do well and benefit the most from the program.

Another aspect to improve is overall program organization. Since it was the pilot year, there were many lessons learned and a few bumps in the road. Now that all the groundwork for running the camp is done, such as creating registration forms, designing a comprehensive curriculum, establishing protocols, and so on, the focus can be on ensuring the successful execution of the program.

Feedback from the coaches and assistant coaches states the realization that the camp should have a more structured curriculum as it would allow for the students to get more out of the limited time. A formal structured curriculum is being developed.

A schedule existed, but the coaches were not able to follow it since the girls learned at a different pace than anticipated. Using the feedback from the campers, parts of the curriculum were reassessed and will be improved in the future.

\section{Conclusions}

A C-STEM Girls Computing and Robotics Leadership Camp for middle school girls was conducted in the summer of 2013. As a pilot program, it successfully accomplished the goals it set out to complete. These goals are to introduce middle school girls to C-STEM related fields, to foster interest in those careers, and to improve their leadership skills so that they can use the CSTEM related knowledge to help and introduce their peers to C-STEM related activities such as robotics clubs and competitions, particularly the RoboPlay Competition in the spring. However, the program still had some issues, which will hopefully work themselves out of the program through successive years of feedback and camps. The program coordinators hope to continue and expand this camp to reach a greater number of middle school girls, starting with the greater Sacramento region and spreading throughout the country.

\section{Acknowledgements}

This work was supported in part by the National Science Foundation under Grant CNS-1132709, IIS-1208690, IIS-1256780, and IIP-1152678. The authors would like to thank the support from the NCWIT AspireIT Middle School Outreach Program and UC Davis University Outreach and 
International Program. We also would like to thank Jason Huang for compiling the survey results.

\section{References}

1. Claire Cain Miller, Curtain Is Rising on a Tech Premiere With (as Usual) a Mostly Male Cast, The New York Times, October 4, 2013, http://www.nytimes.com/2013/10/05/technology/as-tech-start-ups-surge-aheadwomen-seem-to-be-left-behind.html?_r=0

2. Women in High Tech, Globally, March 8, 2013, http://www.catalyst.org/knowledge/women-high-techglobally\#footnote1_m5hpq8d

3. Gary Robbins, Why so few women in engineering? U-T San Diego, September 12, 2013, http://www.utsandiego.com/news/2013/sep/12/women-engineering/

4. UC Davis C-STEM Center, http://c-stem.ucdavis.edu/

5. Women and Information Technology (NCWIT) AspireIT Middle School Outreach Program.

http://www.ncwit.org/programs-campaigns/aspirations-computing/aspireit-2013-programs.

6. Women and Information Technology (NCWIT) Aspiration in Computing, https://www.aspirations.org/

7. 2013 C-STEM GIRL Camp, http://c-stem.ucdavis.edu/students-parents/girls-camp/

8. ABC Channel 7, UC Davis camp encourages tomorrow's female engineers, http://abclocal.go.com/kgo/video?id=9186892\&pid=9186898

9. C-STEM and IEL Robotics Videos, http://iel.ucdavis.edu/projects/imobot/videos.php

10. Barobo, Inc. http://www.barobo.com

11. Lego Mindstorm NXT, http://mindstorm.lego.com

12. Vex Robotics, http://www.vexrobotics.com

13. C-STEM RoboPlay Competition, http://c-stem.ucdavis.edu/roboplay/

14. C/C++ Interpreter Ch, SoftIntegration, Inc., http://www.softintegration.com.

15. Cheng, Harry. "Ten Reasons to Teach and Learn Computer Programming in C" 